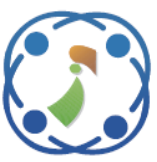

\title{
Improved Bald Eagle Search for Optimal Allocation of D-STATCOM in Modern Electrical Distribution Networks with Emerging Loads
}

\author{
K Radha Rani ${ }^{1 *}$ \\ P Sobha Rani \\ N Chaitanya ${ }^{1}$ \\ Varaprasad Janamala ${ }^{3}$ \\ ${ }^{I}$ R.V.R\& J.C. College of Engineering, Chowdavaram, Guntur, Andhra Pradesh, India \\ ${ }^{2}$ Lakireddy Bali Reddy College of Engineering (Autonomous), Mylavaram, \\ Jawaharlal Nehru Technological University, Kakinada, East Godavari, Andhra Pradesh, India \\ ${ }^{3}$ School of Engineering and Technology, CHRIST (Deemed to be University), Bangalore, Karnataka, India \\ * Corresponding author's Email: korrapatiradharani@gmail.com
}

\begin{abstract}
Currently, modern electrical distribution networks (EDNs) are experiencing high demand with emerging electric vehicle loads and are being planned for specific load requirements such as agricultural loads. In this connection, characterization and optimization of their performance become essential in planning studies. In this paper, optimal reactive power compensation using a distribution-static synchronous compensator (D-STATCOM) is proposed with the aim of loss reduction, voltage profile improvement and voltage stability enhancement different types of loads including agricultural and electric vehicle loads. A recent efficient meta-heuristic approach, improved bald eagle search (IBES), is implemented for solving the proposed optimization problem considering different operational and planning constraints. The simulation results are performed on IEEE 33-bus for different types of load modelling. The computational efficiency of IBES is compared with basic BES and other literature works. From the results, IBES has shown superior computational characteristics than all compared works. On the other hand, the optimal location and size of D-STATCOM caused significant loss reduction, voltage profile improvement and voltage stability enhancement for kinds of loads as experiencing in the modern EDNs.
\end{abstract}

Keywords: Agricultural load, Bald eagle search, Electric vehicle load, Electrical distribution networks, D-STATCOM, Loss minimization, Voltage profile improvement.

\section{Introduction}

Most of the electrical distribution networks (EDNs) are being planned for radial configuration, considering effective protection and operational strategies. However, they are designed with high $\mathrm{r} / \mathrm{x}$ ratio distribution lines and consequently suffer from high distribution losses, low voltage profile, and reduced voltage stability margin [1]. These performance indices are further deteriorating under emerging loads such as electric vehicles [2]. On the other hand, to provide a reliable and effective supply, agricultural loads are being served with separate feeders [3]. Under this scenario, it is essential to strengthen modern distribution networks not only from a technical but also from an economicenvironmental point of view.
Allocation of distributed generation (DG), energy storage systems (ESS), network reconfiguration (NR), integration of capacitor banks (CBs) and regulating transformers are some of the counter measures to cope up variable loading profile effect on EDNs [4]. Due to radial configuration, EDNs suffer with low voltage profile and consequently leads to high distribution losses and low stability margins. The imbalance between reactive power generation and consumption is the major cause for different voltage profile at a bus. Under high reactive power consumption than generation, the bus voltage drops, and it is vice-versa. Thus, reactive power compensation in EDN can play a key role in its operation and control [5].

In the literature, optimal allocation of fixed and switched CBs has been identified as a major $\mathrm{VAr}$ compensation device [6]. However, the introduction 
of flexible AC transmission systems (FACTS) devices to the distribution systems has changed the control of EDNs dramatically [7]. Distribution-static synchronous compensator (D-STATCOM) is one such shunt compensation FACTS device designed suitably for EDNs [8]. Different researchers are focused on D-STATCOM controls for improvement in EDNs' performance. However, the effectiveness of D-STATCOM can be realized significantly when it is integrated in the networks optimally. Identification of potential location and its size is a complex non-linear optimization problem by considering multiple objectives, operational constraints with continuous and discrete variables. Thus, the problem of optimal allocation of DSTATCOM in EDNs is solved by many techniques broadly analytical, sensitivity analysis and heuristic methods [9]. Some of such recent works are reviewed here.

In [10], different sensitivity indices are proposed for identifying optimal location of D-STATCOM in meshed distribution network and its sizing is determined in a repeated approach by aiming loss minimization, voltage profile improvement, voltage stability margin enhancement, cost of energy loss and savings considering seasonal loads and their growth scenarios. A similar kind of D-STATCOM allocation approach based on new voltage stability index (NVSI) can be seen in [11], which is solved for loss minimization and annual energy savings considering different types of load models. Though the proposed stability index (PSI) [10] shown better results than other stability indices adopted from literature, the solution methodology proposed in $[10,11]$ needs lot of computational time due to the need of repetitive load flow for each step increment in size. To contrast these work, genetic algorithm (GA), a well-known and one of the highly adopted heuristic approaches for various engineering optimization problems is adopted for solving the simultaneous allocation of different types of DGs and D-STATCOM [12]. Considering different load models, the impact of DGs and D-STATCOM is analysed on real and reactive power losses, voltage profile and system power factor in IEEE 75-bus power system. In [13], loss sensitivity factor based reduced search space for locations and then flower pollination algorithm (FPA) is used to deduce optimal location form it while simultaneously determining the sizes of real power type DG and DSTATCOM towards optimization of total cost. In [14], gravitational search algorithm (GSA) based multi-objective function using real power loss, voltage deviation and annual energy saving cost is formulated and the D-STATCOM optimal location and sizes are determined in radial distribution networks. In [15], a hybrid whale with grey wolf optimization (WG) is developed for solving the optimal location and sizes of D-STATCOM. In like $[10,11]$, various stability indices are used in [15] to reduce the search space and thus, achieved good computational characteristics. In [16], voltage stability index (VSI) based optimal location of DSTATCOM with pre-defined size is obtained by analysing its impact on distribution losses, voltage profile and voltage stability margins by extracting effective reactive power redistribution in unbalanced distribution network considering high industrial load growth scenarios. In [17], the optimal location and sizes of D-STATCOM and unified power quality conditioner (UPQC) based on power loss index (PLI) and reduced total distribution losses and the comparative study is concluded that the UPQC is outperformed than D-STATCOM in terms of low distribution losses, improved voltage profile and annual energy cost savings. In [18], stability index (SI) and combined power loss sensitivity (CPLS) index are proposed for optimal locations of DSTATCOM and DG, respectively, and their optimal sizes are evaluated using repeated power flow approach considering different types of load models and load growth scenarios in meshed distribution networks. In [19], highest average voltage fluctuation points over a period of one year, and with greatest positive effect on mitigation of voltage unbalance and annual energy loss cost reduction, the optimal location of D-STATCOM is discussed using realtime Europe distribution networks. In [20], considering minimization of annual energy loss cost and annual investment cost, the optimal location, and sizes of D-STATCOM is proposed using GA with discrete and continuous decision variables considering different type of loads. In [21], optimal allocation of D-STATCOM along with photovoltaic (PV) DGs and NR is solved using multi-objective modified flower pollination algorithm (MO-MFPA) towards loss minimization, voltage profile improvement and voltage stability enhancement in radial distribution networks. In [22], considering DSTATCOM as a reactive power compensator, a modified sine cosine algorithm (MSCA) is employed for solving the optimal allocation of for reduction of loss, voltage deviation and voltage stability index inverse. In [23], multi-objective GA (MOGA) for minimizing total harmonic distortion (THD) and investment cost, the problem of optimal allocation of D-STATCOM is solved in unbalanced non-linear loads integrated distribution network. In [24], modified shuffled frog leaping algorithm (MSFLA) is proposed for solving the simultaneous allocation of 


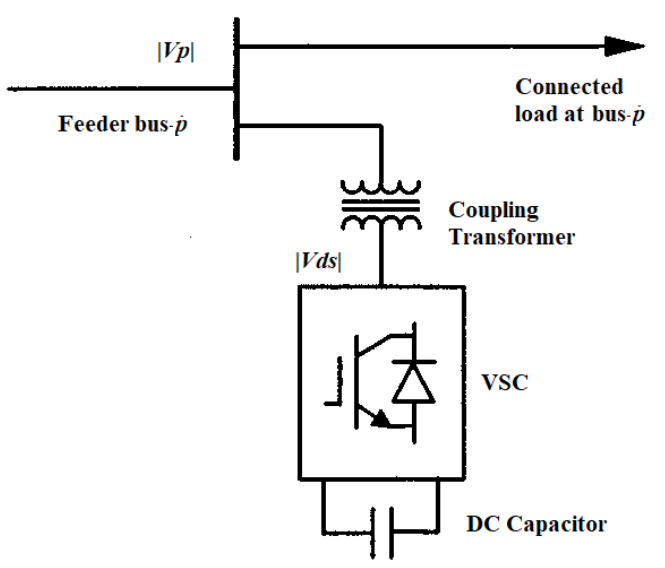

Figure. 1 Schematic diagram of D-STATCOM

DGs and D-STATCOM for loss minimization and voltage stability enhancement in radial distribution networks. In [25], the network losses are modelled using curve fitting technique and later the optimal location along with proper size of D-STATCOM is determined using bat algorithm (BAT).

From these works, many researchers are paid attention on analysis of D-STATCOM impact on EDN performance under different types of loads, loading levels and renewable DGs uncertainty. However, the modern grids are designing for specific loads, such as feeder separation for agricultural loads [3]. Thus, it is important to revise the optimal allocation of D-STATCOM problem considering different type of loads and their composition. On the other side, as highlighted in [26], meta-heuristic approaches are simple and efficient, with less computational efforts to solve complex optimization problems than both analytical and sensitivity analysis-based approaches, this paper introducing a new meta-heuristic algorithm namely bald eagle search (BES) algorithm inspired by hunting behaviour of bald eagle [27]. However, basic BES has slow convergence characteristics due to fixed controlling parameter in search space selection phase. To overcome this, in [28], a dynamic controlling parameter is proposed in improved bald eagle search (IBES) algorithm.

The following are the major contributions of this paper.

- An attempt has been made to determine optimal location and sizes of D-STATCOM considering different emerging types of load models like electric vehicles (EVs) and agricultural along with conventional load models.

- A multi-objective function using distribution losses, voltage profile and voltage stability is presented.
- For the first time, optimal allocation of DSTATCOM problem is solved using IBES and its computational efficiency is compared with literature works.

Rest of the paper is organized as follows: section 2 presents the mathematical modelling of $\mathrm{D}$ STATCOM for load flow study. Section 3 explains the proposed multi-objective optimization problem formulation along with various operational and planning constants. Section 4 describes the concept and mathematical modelling of improved bald eagle optimization algorithm. Section 5 presents the simulation results of proposed methodology and section 6 highlights the major contribution of this research work and future scope.

\section{Modelling of D-STATCOM}

Static synchronous compensator (STATCOM) is one shunt type of FACTS devices used for reactive power management in transmission system as well as at distribution networks. It is like the rotating synchronous condenser's static equivalent, except it generates/absorbs reactive power at a higher pace due to the absence of moving components. It functions as a static var compensator (SVC), with capacitive or inductive output currents that are regulated to control the bus voltage to which it is linked. In theory, it accomplishes the same voltage regulation as the SVC, but more robustly since, unlike the SVC, its functioning is not hampered by the presence of low voltages. It works well with sophisticated energy storage facilities, allowing for a variety of novel applications such as energy deregulation and network security. D-STATCOM is a FACTS device at distribution network known as D-FACTS that may inject or absorb reactive current at the linked bus. It comprises of a three-phase voltage source converter (VSC)/ current source converter (CSC), a DC capacitor/ DC voltage source/ ESS and an AC filter, which is often connected to the distribution network through a coupling transformer as shown in Fig. 1.

In general, D-STATCOM functions as a synchronized voltage source that can manage the magnitude and angle of AC bus voltages, allowing it to effectively handle active and reactive power exchanges from/to grids by working in either inductive or capacitive mode. However, in this paper, D-STATCOM is believed to solely provide reactive power compensation and to successfully manage grid-bus voltage and consequently reduction in losses, improvement in voltage profile, voltage stability enhancement, reliability, operational cost, reduction of THD and can effectively use for load balance. The 
schematic diagram of a two-bus distribution branch connected between utility bus- $p$ and D-STATCOM bus- $d s$.

The complex power flow from D-STATCOM is determined by,

$$
S_{d s}=P_{d s}+j Q_{d s}=V_{d s} I_{d s}^{*}=V_{d s}\left(\frac{V_{d s}-V_{p}}{z_{d s}}\right)^{*}
$$

where $S_{d s}, P_{d s}$ and $Q_{d s}$ are the complex, real and reactive powers at bus- $d s$, respectively; $V_{d s}$ and $I_{d s}$ are the voltage and current of D-STATCOM; $Z_{d s}$ is the impedance of D-STATCOM includes VSC and transformer; $V_{d s}$ is the grid-bus voltage.

The following expressions can be obtained for real and reactive power flows form D-STATCOM considering $\quad V_{d s}=\left|V_{d s}\right|\left(\cos \delta_{d s}+j \sin \delta_{d s}\right) \quad$ and $Y_{d s}=1 / Z_{d s}=G_{d s}-j B_{d s}$.

$$
\begin{gathered}
P_{d s}=-\left|V_{d s}\right|\left|V_{p}\right|\left[G_{d s} \cos \left(\delta_{d s}-\delta_{p}\right)+\right. \\
\left.G_{d s} \sin \left(\delta_{d s}-\delta_{p}\right)\right]\left|V_{d s}\right|^{2} G_{d s} \\
Q_{d s}=-\left|V_{d s}\right|^{2} B_{d s}-\left|V_{d s}\right|\left|V_{p}\right| \\
{\left[G_{d s} \sin \left(\delta_{d s}-\delta_{p}\right)-B_{d s} \cos \left(\delta_{d s}-\delta_{p}\right)\right]}
\end{gathered}
$$

where $Y_{d s}, Y_{d s}$ and $Y_{d s}$ are the admittance, conductance and susceptance of D-STATCOM, respectively; $\delta_{d s}$ and $\delta_{p}$ are the load angles of bus$d s$ and $p$, respectively.

For simplification, considering D-STATCOM is a lossless device, i.e., $G_{d s}=0$ and $\delta_{d s} \cong \delta_{p}$, then Eq. (2) and Eq. (3) becomes as follows:

$$
P_{d s}=0 \& Q_{d s}=-\left|V_{d s}\right|^{2} B_{d s}+\left|V_{d s}\right|\left|V_{p}\right| B_{d s}
$$

According to Eq. (4), under ideal conditions, DSTATCOM cannot be able to provide active power support to the utility. Also, it can generate reactive power to the grid if $\left|V_{p}\right|>\left|V_{d s}\right|$ for which $Q_{d s}$ becomes negative. On the other hand, it absorbs reactive power from grid if $\left|V_{p}\right|<\left|V_{d s}\right|$ for which $Q_{d s}$ becomes positive.

In case, if D-STATCOM equipped with any ESS in place of capacitor, then by controlling its voltage angle $\delta_{d s}$, it is possible to exchange real power flows from/to the utility. The permissible range is $\left[0^{0}, 180^{\circ}\right]$.

\section{Problem formulation}

The literature focuses on loss reduction, voltage profile improvement, and voltage stability enhancement as the main technological goals. Total cost reduction. In this research, the optimal allocation of D-STATCOM problem is solved for technical benefits and economic benefits separately.

\subsection{Objective function}

A multi-objective optimization problem defined in Eq. (5) is framed using real power loss, voltage deviation and overall stability index, mathematically given by,

$$
\begin{aligned}
& O F=P_{\text {loss }}+V D+V S I \\
& P_{\text {loss }}=\sum_{k=1}^{n b r} I_{k}^{2} r_{k} \\
& V D=\frac{1}{n b} \sum_{i=1}^{n b} \sqrt{1-\left|V_{i}\right|^{2}} \\
& \quad V S I=\min \left\{\left|V_{p}\right|^{4}-4\left(x_{k} P_{q}-r_{k} Q_{q}\right)^{2}-\right. \\
& \left.4\left(r_{k} P_{q}+x_{k} Q_{q}\right)\left|V_{p}\right|^{2}, \forall q=2: n b\right\}
\end{aligned}
$$

\subsection{Operational constraints}

A solution to the suggested $\mathrm{OF}$ is found by considering the following bus voltage magnitude constraint, branch thermal limit, D-STATCOMs reactive power capacity limits, given by Eqs. (9-11), respectively.

$$
\begin{aligned}
& \left|V_{i}\right|^{\text {min }} \leq\left|V_{i}\right| \leq\left|V_{i}\right|^{\text {max }} ; \forall i=1: n b \\
& S_{k}=S_{k}^{\max } ; \forall k=1: n b r \\
& \sum_{k=1}^{n d s} Q_{d s, k} \ll \sum_{i=1}^{n b} Q_{d, i}
\end{aligned}
$$

where $P_{\text {loss }}, V D$ and VSI are the total distribution losses, average voltage deviation w.r.t. substation bus voltage magnitude and overall system voltage stability index (i.e., maximum of all bus indices) at a specific time, respectively; $k$ is the branch index connected between buses $p$ and $q ; S_{k}, S_{k}^{\max } I_{k}$, $r_{k}$ and $x_{k}$ are the apparent power flow and its maximum limit, current flow, resistance and reactance of branch- $k$, connected between bus- $p$ and bus- $q$, respectively; $P_{q}$ and $Q_{q}$ are the real and reactive power loads at bus- $q$, respectively; $\left|V_{i}\right|$, $\left|V_{i}\right|^{\text {min }}$ and $\left|V_{i}\right|^{\text {max }}$ are the voltage magnitude of bus- $i$, and its minimum and maximum limits, respectively; $Q_{d s, k}$ and $Q_{d, i}$ are the reactive power injection by D-STATCOM bus- $k$, and reactive power load at bus-i, respectively; $n b, n b r$, and $n d s$ are the number of buses, number of branches, number of DSTATCOMs in the network, respectively. 


\section{Proposed solution methodology}

Alsattar, H.A et al. introduced a new metaheuristic optimization algorithm called bald eagle search (BES) in 2020, which was inspired by the hunting behavior of bald eagles while searching for prey such as fish [27]. The BES optimization process is divided into three stages: selecting space from the air, searching extensively in space, and finally swooping down on the selected prey.

\subsection{Bald eagle search algorithm}

In the first selection stage, the search space is randomly selected by blades using their previous search knowledge, as given by,

$$
l_{i, \text { new }}=l_{\text {best }}+\tau \times r\left(l_{\text {mean }}-l_{i}\right)
$$

Here $r$ is a random number between 0 and 1; $l_{i, \text { new }}$ and $l_{i}$ are the new and current search locations, respectively; $l_{\text {best }}$ is the current best location chosen by bald eagle; $l_{\text {mean }}$ is the mean of all earlier hunting search spaces and indicates the absorption of all information towards that location; $\tau$ is the controlling parameter of BES for changing eagles location.

In the second stage, the eagle moves in a spiral shape to speed up the search for prey in the previously specified search zone. The best location for swooping up is expressed by,

$$
\begin{aligned}
& l_{i, n e w}=l_{i}+y_{i}\left(l_{i}-l_{i+1}\right)+x_{i}\left(l_{i}-l_{\text {mean }}\right) \\
& x_{i}=\frac{x r_{i}}{\max (|x r|)} \& y_{i}=\frac{y r_{i}}{\max (|x r|)} \\
& x r_{i}=r_{i} \times \sin \left(\theta_{i}\right) \& y r_{i}=r_{i} \times \cos \left(\theta_{i}\right) \\
& \theta_{i}=a \times \pi \times \text { rand \& } r_{i}=\theta_{i}+R \times \text { rand }
\end{aligned}
$$

where $a$ is a parameter that ranges from 5 to 10 for selecting the corner between point searches in the centre point, and $R$ is a parameter that ranges from 0.5 to 2 for determining the number of search cycles.

In the last swooping stage, eagle starts moving towards prey in a swing movement as expressed by,

$$
\begin{aligned}
& l_{i, \text { new }}=\operatorname{rand} \times l_{\text {best }}+x_{1 i}\left(l_{i}-c_{1} l_{\text {mean }}\right)+ \\
& +y_{1 i}\left(l_{i}-c_{2} l_{\text {best }}\right)
\end{aligned}
$$

where $c_{1}$ and $c_{2}$ exists between $[1,2]$.

$$
x_{1 i}=\frac{x r_{1 i}}{\max (|x r|)} \& y_{1 i}=\frac{y r_{1 i}}{\max (|x r|)}
$$

$$
\begin{aligned}
& x r_{1 i}=r_{i} \times \sinh \left(\theta_{i}\right) \& y r_{1 i}=r_{i} \times \cosh \left(\theta_{i}\right) \\
& \theta_{i}=a \times \pi \times \text { rand \& } r_{i}=\theta_{i}
\end{aligned}
$$

\subsection{Improved bald eagle search algorithm}

In the basic BES, the range of controlling parameter $\boldsymbol{\tau}$ is defined between 1.5 and 2. Thus, it has a slow convergence rate due to the use of a fixed controlling parameter in the search space selection. To address this, the improved bald eagle search (IBES) method [28] introduces an adaptive control parameter for achieving good search characteristics in both the exploration and exploitation phases.

$$
\tau=\left[1.5 \times \frac{\left(k_{\max }-k+1\right)}{k_{\max }}\right]
$$

where $k$ and $k_{\max }$ are the present iteration count and number of maximum iterations, respectively.

\subsection{Optimization procedure}

The steps involved in IBES for solving the DSTATCOM allocation problem are presented here:

St. 1) Define number of populations, number of decision variables (i.e., number, location, and sizes of D-STATCOMs), and maximum number of iterations.

St. 2) Initialize randomly eagles search spaces $l_{i}$ and calculate the fitness value of each location using Eq. (5) and store the best location.

St. 3) Set iteration count $i t=1$.

St. 4) Update the locations using Eq. (12) for basic BES or using both Eq. (12) and Eq. (21) for IBES.

St. 5) Evaluate the $O F$ value for the locations and update best location found in step. 2 .

St. 6) Update the locations using Eq. (13) and evaluate the $O F$ value with these new locations.

St. 7) Evaluate the $O F$ value for the locations obtained in St. 5 and update best location found in St. 4.

St. 8) Update the locations using Eq. (17) and evaluate the OF value with these new locations.

St. 9) Evaluate the $O F$ value for the locations obtained in step. 7 and update best location found in step. 6 .

St. 10) If $k$ does not reach maximum, repeat St. 4 to St. 9 else, stop the process. 
Table 1. Results of D-STATCOM size in kVAr and location for different load models using IBES

\begin{tabular}{|c|c|c|c|c|c|c|c|c|}
\hline $\begin{array}{l}\text { Load } \\
\text { model }\end{array}$ & Case \# & $\begin{array}{l}\text { Pload }_{\text {load }} \\
(\mathbf{k W}) \\
\end{array}$ & $\begin{array}{l}\text { Qload } \\
\text { (kVAr) }\end{array}$ & $\begin{array}{l}\text { D-STATCOM } \\
\text { Size (bus) }\end{array}$ & $\begin{array}{l}P_{\text {loss }} \\
(\mathbf{k W}) \\
\end{array}$ & $\begin{array}{l}\text { Qloss } \\
\text { (kVAr) }\end{array}$ & $\begin{array}{l}\text { VD } \\
\text { (p.u.) } \\
\end{array}$ & VSI \\
\hline \multirow{2}{*}{$\mathrm{CP}$} & 1 & 3715.00 & 2300.00 & - & 210.548 & 142.744 & 0.0546 & 0.6675 \\
\hline & 2 & 3715.00 & 1015.00 & $1285(30)$ & 150.694 & 103.462 & 0.0425 & 0.7075 \\
\hline \multirow{2}{*}{ Residential } & 1 & 3558.64 & 1875.37 & - & 164.338 & 111.022 & 0.0480 & 0.7044 \\
\hline & 2 & 3586.77 & 953.89 & $1220(30)$ & 133.217 & 90.833 & 0.0398 & 0.7303 \\
\hline \multirow{2}{*}{ Industrial } & 1 & 3683.61 & 1705.06 & - & 167.603 & 113.407 & 0.0482 & 0.7022 \\
\hline & 2 & 3689.04 & 866.26 & $1265(30)$ & 141.453 & 96.497 & 0.0405 & 0.7270 \\
\hline \multirow{2}{*}{ Commercial } & 1 & 3466.64 & 1940.30 & - & 159.316 & 107.508 & 0.0473 & 0.7090 \\
\hline & 2 & 3510.72 & 999.29 & $1190(30)$ & 126.854 & 86.419 & 0.0392 & 0.7346 \\
\hline \multirow{2}{*}{ EVs } & 1 & 3322.46 & 1898.50 & - & 143.677 & 96.744 & 0.0448 & 0.7237 \\
\hline & 2 & 3386.16 & 1018.49 & $1150(30)$ & 115.493 & 78.469 & 0.0376 & 0.7461 \\
\hline \multirow{2}{*}{ Agriculture } & 1 & 3699.78 & 2102.68 & - & 193.787 & 131.262 & 0.0524 & 0.6796 \\
\hline & 2 & 3703.10 & 972.51 & $1275(30)$ & 147.168 & 100.807 & 0.0418 & 0.7141 \\
\hline \multirow{2}{*}{ Composite } & 1 & 3571.73 & 1871.57 & - & 165.483 & 111.820 & 0.0482 & 0.7033 \\
\hline & 2 & 3597.16 & 948.24 & $1225(30)$ & 134.186 & 91.513 & 0.0400 & 0.7295 \\
\hline
\end{tabular}

\section{Results and discussion}

The proposed IBES is implemented in the environment of MATLAB R2021b to obtain the optimal position and size of the D-STATCOM device considering different load models. To evaluate the performance characteristics of the proposed IBES, IEEE 33-bus [29] test system is chosen. Simulations are performed in two cases: 1 ) without D-STATCOM and 2) with D-STATCOM. The minimum discrete size of D-STATCOM is chosen as $5 \mathrm{kVAr}$ and the maximum is the total $\mathrm{kVAr}$ demand of the network. It aims to integrate only one D-STATCOM into the entire network. The maximum number of iterations and the number of populations is chosen as 50 .

In this section, D-STATCOM location and sizes are optimized considering different types of load models, namely, residential, industrial, and commercial, and their composition. For the composite load model, 25\% residential, 20\% commercial, $30 \%$ industrial, $10 \%$ electric vehicle, and $15 \%$ agriculture loads are assumed on each bus. The real and reactive power exponents for different kind of loads are taken from [30-31]. In addition, the performance of the proposed IBES is compared with other literature works considering the constant power load model.

The results of network performance for each type of load are given in Table 1 before and after the integration of D-STATCOM into the network. For the constant power (CP) load model, the network experienced with real and reactive power losses of $210.5484 \mathrm{~kW}$ and $142.7439 \mathrm{kVAr}$, respectively. Correspondingly, it has a VD and VSI of 0.0546 and
0.6675 , respectively. In addition, the minimum voltage magnitude of 0.9039 at bus-18 is observed.

According to the optimal solution by IBES, the size of D-STATCOM for this load model is obtained as $1285 \mathrm{kVAr}$ at bus-30. Thus, the network performance has improved significantly as follows: Real and reactive power losses are reduced by $150.6942 \mathrm{~kW}$ and $103.4624 \mathrm{kVAr}$, respectively. The voltage profile is improved such that the VD and VSI are decreased to 0.0425 and 0.7075 , respectively. On the other hand, the minimum voltage magnitude in the entire network is raised to 0.9171 at bus- 18 .

Similarly, the results for all other types of load models and the network performance before and after the integration of D-STASTCOM optimally into the network by IBES are given in Table 1. From the results, it can be evident that the D-STATCOM causes the network to improve performance in all aspects, irrespective of load type, if it is properly sized and integrated into the network. The voltage profiles of the network for different load models are given in Fig. 2 and Fig. 3 for before and after integration of D-STATCOM, respectively. From these figures, it can be said that the network voltage profile is smoother with D-STATCOM and thus results for low voltage deviation and improved voltage stability in all types of load models.

Also, the computational efficiency of the proposed IBES is compared with other meta-heuristic algorithms used in the literature. To compare network performance in all its aspects, the load flow is performed for the solution provided by each algorithm in a brute-force technique. The comparison is given in Table 2. From the results, it can be concluded that the proposed IBES outperforms than 
Table 2. Comparison of IBES with literature works for constant power load model

\begin{tabular}{llllllll}
\hline \hline \multirow{2}{*}{ Parameter } & \multirow{2}{*}{ Base } & \multicolumn{2}{l}{ D-STATCOM } & & & \\
\cline { 3 - 7 } & & NVSI [11] & GSA [14] & PLI [17] & BAT [25] & BES & IBESA \\
\hline kVAr (bus-\#) & - & $1250(30)$ & $927(27)$ & $1691(29)$ & $1150(30)$ & $1280(30)$ & $1285(30)$ \\
P $_{\text {loss }}$ (kW) & 210.548 & 150.732 & 169.708 & 155.993 & 151.301 & 150.695 & $\mathbf{1 5 0 . 6 9 4}$ \\
Q $_{\text {loss }}$ (kVAr) & 142.744 & 103.414 & 177.382 & 108.107 & 103.601 & 103.452 & 103.462 \\
VD (p.u.) & 0.0546 & 0.0428 & 0.0480 & 0.0392 & 0.0437 & 0.0425 & 0.0425 \\
V $_{\text {min }}$ (p.u.) (bus-18) & 0.9039 & 0.9168 & 0.9132 & 0.9211 & 0.9158 & 0.9171 & 0.9171 \\
VSI & 0.6675 & 0.7065 & 0.6954 & 0.7197 & 0.7034 & 0.7074 & 0.7075 \\
\hline
\end{tabular}

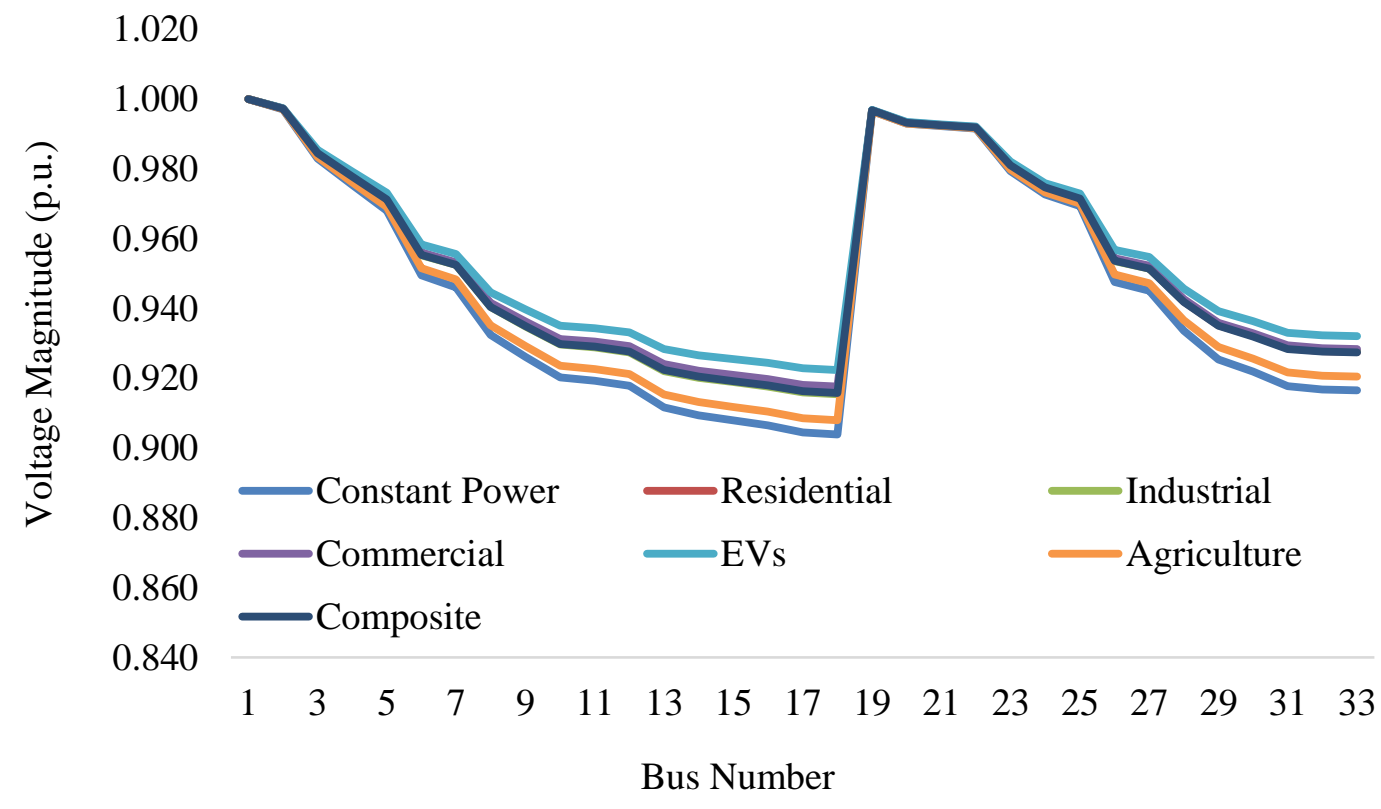

Figure. 2 Voltage profile for different types of loads for case 1

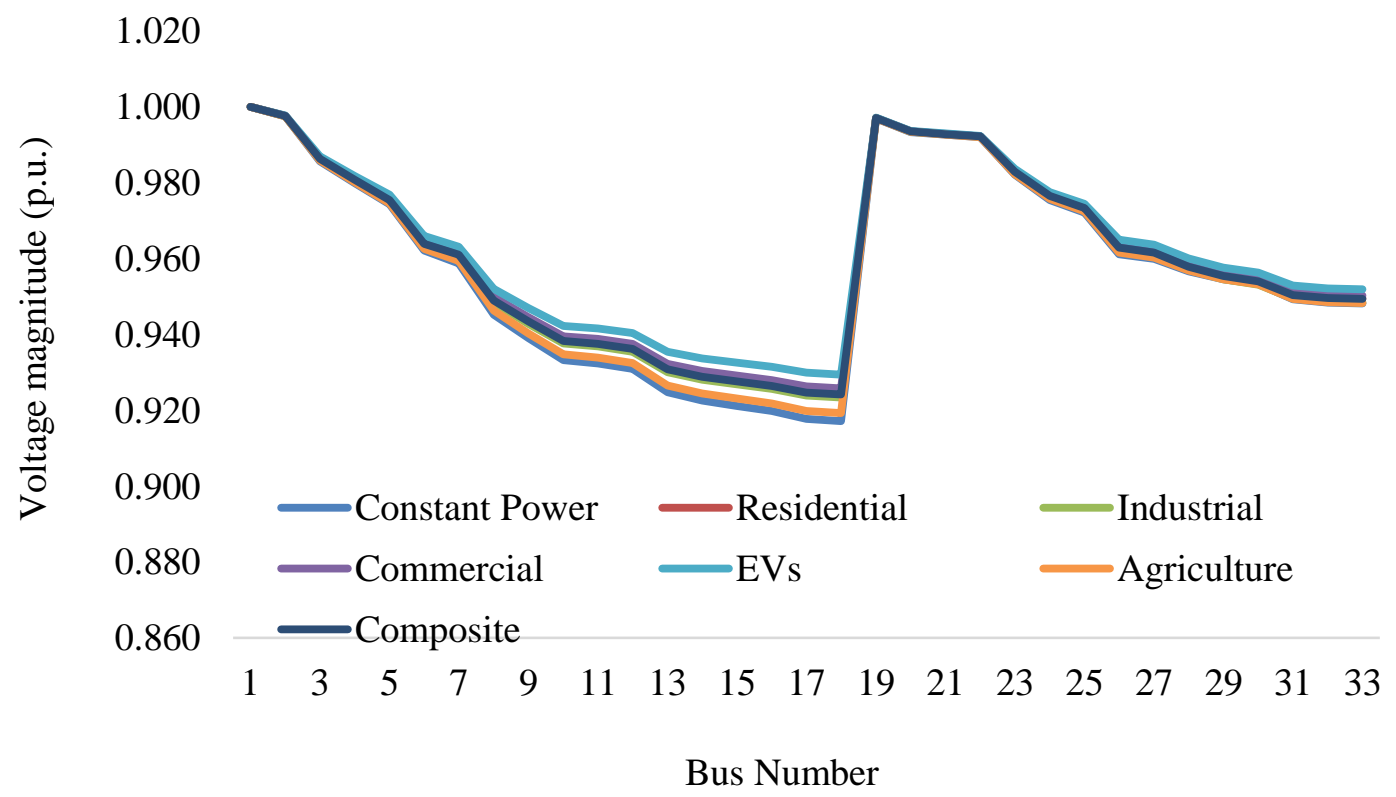

Figure. 3 Voltage profile for different types of loads for case 2 
NVSI [11], GSA [14], PLI [17], BAT [25] and basic BES by its global solution.

\section{Conclusion}

In this paper, the optimum reactive power compensation using a distribution-static synchronous compensator (D-STATCOM) is proposed with the purpose of lowering losses, improving voltage profiles, and improving voltage stability for various load models. The suggested optimization problem is solved using improved bald eagle search (IBES), a contemporary efficient meta-heuristic approach that takes into account numerous operational and planning constraints. The IEEE 33-bus was used to simulate the results under many scenarios. In terms of global optima, IBES is compared to literature works and basic BES. As indicated by the global optima that arise, the comparison analysis demonstrates that IBES has superior features in solving challenging non-linear optimization problems with discrete and continuous variables. The proper location and size of D-STATCOM, on the other hand, resulted in significant loss reduction and voltage profile improvement even in contemporary EDNs with a diverse mix of loads such as residential, industrial, commercial, agricultural, and electric vehicle loads. The optimal integration of DSTATCOM in an IEEE 33-bus system results in a 28.43 percent reduction in distribution loss to $150.694 \mathrm{~kW}$ from $210.548 \mathrm{~kW}$. The impact of several D-STATCOMs in compact sizes, on the other hand, needs to be examined and considered as a separate study.

\section{Conflicts of interest}

The authors declare no conflict of interest.

\section{Author contributions}

The supervision, review of work and project administration, has been done by first author. The paper background work, conceptualization, and methodology have been done by second author. The dataset collection and editing draft is prepared by third author. The program implementation, result analysis and comparison, and visualization have been done by fourth author.

\section{References}

[1] R. Li, W. Wang, Z. Chen, J. Jiang, and W. Zhang, "A review of optimal planning active distribution system: Models, methods, and future researches", Energies, Vol. 10, No. 11, p. 1715, 2017.
[2] H. S. Das, M. M. Rahman, S. Li, and C.W. Tan, "Electric vehicles standards, charging infrastructure, and impact on grid integration: A technological review", Renewable and Sustainable Energy Reviews, Vol. 120, p. 109618, 2020.

[3] N. Padole, R. M. Moharil and A. Munshi, "Solar Photovoltaic (SPV) Power Plant Connected Agricultural Feeder Performance Analysis", In: Proc. of 2021 International Conference on Electrical, Computer, Communications and Mechatronics Engineering, Mauritius, India, pp. 1-7, 2021.

[4] M. Shaaban, and J. O. Petinrin, "Renewable energy potentials in Nigeria: Meeting rural energy needs", Renewable and Sustainable Energy Reviews, Vol. 29, pp. 72-84, 2014.

[5] A. A. Téllez, G. López, I. Isaac, and J. W. González, "Optimal reactive power compensation in electrical distribution systems with distributed resources", Review. Heliyon, Vol. 4, No. 8, p. e00746, 2018.

[6] M. Resener, S. Haffner, L. A. Pereira, and P. M. Pardalos, "Optimization techniques applied to planning of electric power distribution systems: a bibliographic survey", Energy Systems, Vol. 9, No. 3, pp. 473-509, 2018.

[7] J. M. M. Ortega, E. Acha, S. García, and A. G. Expósito, "Overview of power electronics technology and applications in power generation transmission and distribution", Journal of Modern Power Systems and Clean Energy, Vol. 5, No. 4, pp. 499-514, 2017.

[8] M. Ebeed, S. Kamel, S. H. A. Aleem, and A. Y. Abdelaziz, "Optimal allocation of compensators", Electric Distribution Network Planning. Power Systems, pp. 321-353. Springer, Singapore, 2018.

[9] R. Sirjani, and A. R. Jordehi, "Optimal placement and sizing of distribution static compensator (D-STATCOM) in electric distribution networks: A review", Renewable and Sustainable Energy Reviews, Vol. 77, pp. 688-694, 2017.

[10] A. R. Gupta and A. Kumar, "Optimal placement of D-STATCOM using sensitivity approaches in mesh distribution system with time variant load models under load growth", Ain Shams Engineering Journal, Vol. 9, No. 4, pp. 783-799, 2018.

[11] A. R. Gupta and A. Kumar, "Impact of various load models on D-STATCOM allocation in DNO operated distribution network", Procedia Computer Science, Vol. 125, pp. 862-870, 2018. 
[12] B. Singh and M. K. Yadav, "GA for enhancement of system performance by DG incorporated with D-STATCOM in distribution power networks", Journal of Electrical Systems and Information Technology, Vol. 5, No. 3, pp. 388-426, 2018.

[13] M. V. Bhat and N. Manjappa, "Flower pollination algorithm based sizing and placement of DG and D-STATCOM simultaneously in radial distribution systems", In: Proc. of 2018 20th National Power Systems Conference, NIT Tiruchirappalli, India, pp. 1-5, 2018.

[14] A. K. Arya, A. Kumar, and S. Chanana, "Analysis of distribution system with DSTATCOM by gravitational search algorithm (GSA)", Journal of the Institution of Engineers (India): Series B, Vol. 100, No. 3, pp. 207-215, 2019.

[15] V. Tejaswini and D. Susitra, "Optimal Location and Compensation Using D-STATCOM: A Hybrid Hunting Algorithm", Journal of Control, Automation and Electrical Systems, Vol. 32, pp. 1002-1023, 2021.

[16] A. R. Gupta, and A. Kumar, "Reactive power deployment and cost benefit analysis in DNO operated distribution electricity markets with DSTATCOM", Frontiers in Energy, Vol. 13, No. 1, pp. 86-98, 2019.

[17] A. R. Gupta, and A. Kumar, "Performance analysis of radial distribution systems with UPQC and D-STATCOM", Journal of The Institution of Engineers (India): Series B, Vol. 98, pp. 415-422, 2017.

[18] A. R. Gupta, "Effective Utilisation of Weakly Meshed Distribution Network with DG and DSTATCOM", Journal of The Institution of Engineers (India): Series B, Vol. 102, pp. 679690, 2021.

[19] G. Fernández, A. Martínez, N. Galán, J. B. Fuertes, J. M. C. Alba, P. López, S. Stukelj, E. Daridou, A. Rezzonico and D. Ioannidis, "Optimal D-STATCOM Placement Tool for Low Voltage Grids", Energies, Vol. 14, No. 14, 4212, 2021.

[20] C. M. C. Pérez, D. E. T. Rodríguez, O. D. Montoya, and D. A. G. Ramírez, "Optimal Placement and Sizing of D-STATCOM in Radial and Meshed Distribution Networks Using a Discrete-Continuous Version of the Genetic Algorithm", Electronics, Vol. 10, No. 12, 1452, 2021.

[21] S. Ganesh and R. Kanimozhi, "Meta-heuristic technique for network reconfiguration in distribution system with photovoltaic and D-
STATCOM", IET Generation, Transmission \& Distribution, Vol. 12, No. 20, pp. 4524-4535, 2018.

[22] M. Ebeed, S. Kamel, and A. R. Youssef, "Optimal Integration of D-STATCOM in RDS by a Novel Optimization Technique", In: Proc. of 2018 Twentieth International Middle East Power Systems Conference, Cairo University, Egypt, pp. 638-642, 2018.

[23] M. H. Nazari, A. Khodadadi, A. Lorestani, S. H. Hosseinian, and G. B. Gharehpetian, "Optimal multi-objective D-STATCOM placement using MOGA for THD mitigation and cost minimization", Journal of Intelligent \& Fuzzy Systems, Vol. 35, No. 2, pp. 2339-2348, 2018.

[24] M. Moazzami, G. B. Gharehpetian, H. Shahinzadeh, and S. H. Hosseinian, "Optimal locating and sizing of DG and D-STATCOM using Modified Shuffled Frog Leaping Algorithm", In: Proc. of 2017 2nd Conference on Swarm Intelligence and Evolutionary Computation, Kerman, Iran, pp. 54-59, 2017.

[25] T. Yuvaraj, K. Ravi, and K. R. Devabalaji, "DSTATCOM allocation in distribution networks considering load variations using bat algorithm", Ain Shams Engineering Journal, Vol. 8, No. 3, pp. 391-403, 2017.

[26] H. R. Moshtaghi, A. T. Eshlaghy, and M. R. Motadel, "A comprehensive review on metaheuristic algorithms and their classification with novel approach", Journal of Applied Research on Industrial Engineering, Vol. 8, No. 1, pp. 6389, 2021.

[27] H. A. Alsattar, A. A. Zaidan, and B. B. Zaidan, "Novel meta-heuristic bald eagle search optimisation algorithm", Artificial Intelligence Review, Vol. 53, No. 3, pp. 2237-2264, 2020.

[28] A. Ramadan, S. Kamel, M. H. Hassan, T. Khurshaid, and C. Rahmann, "An Improved Bald Eagle Search Algorithm for Parameter Estimation of Different Photovoltaic Models", Processes, Vol. 9, No. 7, p. 1127, 2021.

[29] S. H. Dolatabadi, M. Ghorbanian, P. Siano, and N. D. Hatziargyriou, "An Enhanced IEEE 33 Bus Benchmark Test System for Distribution System Studies", IEEE Transactions on Power Systems, Vol. 36, No. 3, pp. 2565-2572, 2020.

[30] A. Arif, Z. Wang, J. Wang, B. Mather, H. Bashualdo, and D. Zhao, "Load modeling-A review", IEEE Transactions on Smart Grid, Vol. 9, No. 6, pp. 5986-5999, 2017.

[31] V. Janamala and T. K. S. Pandraju, "Static voltage stability of reconfigurable radial distribution system considering voltage dependent load models", Mathematical 
Received: December 20, 2021. Revised: February 19, 2022.

Modelling of Engineering Problems, Vol. 7, No.

3, pp. 450-458, 2020. 